05

\title{
Слоевые нанопроволоки - матричный синтез, структура и магнитные свойства
}

\author{
( Д.Л. Загорский ${ }^{1,2}$, И.М. Долуденко ${ }^{1}$, Д.А. Черкасов ${ }^{1}$, О.М. Жигалина ${ }^{1,3}$, Д.Н. Хмеленин ${ }^{1}$, \\ И.М. Иванов ${ }^{1,3}$, А.А. Бухараев ${ }^{4}$, Д.А. Бизяев ${ }^{4}$, Р.И. Хайбуллин ${ }^{4}$, С.А. Шаталов ${ }^{1}$ \\ ${ }^{1}$ Институт кристаллографии им. А.В. Шубникова ФНИЦ „Кристаллография и фотоника“ РАН, \\ Москва, Россия \\ ${ }^{2}$ Московский университет нефти и газа им. И.М. Губкина, \\ Москва, Россия \\ ${ }^{3}$ Московский государственный технический университет им. Н.Э. Баумана, \\ Москва, Россия \\ ${ }^{4}$ Казанский фризико-технический институт им. Е.К. Завойского, \\ Федеральный исследовательский центр „Казанский научный центр РАН“, \\ Казань, Россия \\ E-mail: dzagorskiy@gmail.com
}

Поступила в Редакцию 15 апреля 2019 г.

В окончательной редакции 22 апреля 2019 г.

Принята к публикации 24 апреля 2019 г.

\begin{abstract}
Методом матричного синтеза в порах полимерной трековой мембраны были синтезированы нанопроволоки диаметром $100 \mathrm{~nm}$, состоящие из чередующихся слоев $\mathrm{Ni} / \mathrm{Cu}$ и $\mathrm{Co} / \mathrm{Cu}$ с толщинами слоев от 10 до $500 \mathrm{~nm}$. Подобраны составы и режимы „импульсного“ электроосаждения нанопроволок. Предложен режим роста нанопроволок с протеканием одинакового заряда в импульсе. Показано, что уменьшение заряда в импульсе сначала ведет к уменьшению толщины слоя (до $10-15 \mathrm{~nm}$ ), а затем наблюдается „перемешивание“ элементного состава слоев и/или образование в нанопроволоке наноструктур типа „стержень-оболочка“ („core-stick“). Методом магнитометрии определены коэрцитивная сила $(15-30 \mathrm{mT})$ и остаточная намагниченность слоевых нанопроволок. Петли магнитного гистерезиса, при регистрации в „out-of-plane“ и „in-plane“ геометриях измерения, подобны по форме и параметрам при толщине слоев в нанопроволоке 50-100 nm. Для нанопроволок с более толстыми слоями, 250 и $500 \mathrm{~nm}$, наблюдается заметное различие в кривых гистерезиса, обусловленное магнитной анизотропией (появление оси легкого намагничивания вдоль оси нанопроволоки) и взаимным влиянием близкорасположенных нанопроволок. Магнитно-силовая микроскопия единичных нанопроволок выявила в них области намагниченности с геометрическими размерами $\sim 100-150 \mathrm{~nm}$. Показано, что внешним магнитным полем $(16 \mathrm{mT}$, вдоль оси нанопроволоки) удается частично перемагнитить нанопроволоку.
\end{abstract}

Ключевые слова: гетероструктурные нанопроволоки, гальваническое осаждение, магнитометрия, микроскопия.

DOI: $10.21883 /$ FTT.2019.09.48111.19N

\section{1. Введение}

Среди наноматериалов большой интерес вызывают одномерные структуры - нанопроволоки (наностержни, нанонити). Одним из способов получения таких нанопроволок (НП) является метод матричного синтеза. Суть метода состоит в заполнении требуемым материалом пор в специально приготовленной матрице - темплате. В качестве темплата могут выступать различные пористые материалы. Чаще всего используются пленки пористого оксида алюминия и полимерные трековые мембраны. Вещества, „загружаемые“ в поры, также могут быть самыми различными - полимеры, водорастворимые кристаллы, металлы. Существует несколько способов заполнения пор, среди них наиболее распространены электрохимический и химический методы. В настоящей работе в качестве пористых матриц были использованы полимерные трековые мембраны, в поры которых электрохимическим (гальваническим) методом осаждались металлы. Такой способ получения НП известен давно (примерно, с начала 90-х годов прошлого столетия, см. [1-3]) и достаточно распространен ввиду своей простоты, дешевизны и возможности варьировать многие параметры получаемых НП за счет изменения характеристик матрицы и параметров электроосаждения [4]. Метод динамично развивался: если в первые годы были синтезированы простые НП из одного металла, то затем получаемые структуры усложнялись и были синтезированы многокомпонентные НП с различными комбинациями элементов и их распределением в НП.

Многокомпонентные НП можно разделить на два типа: гомогенные (сплавы) и гетерогенные (слоевые). Отметим, что получение обоих типов структур обусловлено возможностями гальванического метода осаждения. Перспективность создания НП из „сплавов“ связана с возможностью варьирования свойств, получения новых, 
в ряде случаев, более высоких характеристик (что достигается и при получении классических, „объемных“ сплавов). Получение таких НП рассмотрено во многих статьях и обзорах. Известно, что при гальваническом осаждении металлических НП в поры трековых мембран используется водный раствор соответствующих солей металлов. Сам процесс проводится в гальванической ячейке, при этом ионы металла из раствора поступают в поры матрицы (трековой мембраны) при протекании тока. Различные металлы имеют различные потенциалы осаждения, поэтому одновременное осаждение всех металлов (в случае сплавов) достигается в том случае, когда прилагаемый потенциал превосходит потенциалы осаждения всех металлов-участников. Некоторые аспекты матричного синтеза, структуры и свойств железосодержащих сплавов описаны в наших работах $[5,6]$.

Не меньший интерес представляет и другой тип слоевые НП. Такие НП состоят из чередующихся слоев, различающихся по элементному и фазовому составу. При этом можно варьировать состав, длину (толщину) и количество различных типов слоев. В целом, количество возможных комбинаций здесь бессчетно. При гальваническом осаждении слоевой НП (в простейшем случае двухкомпонентной) широко используются возможности электрохимии [7-9]. В данном случае используется периодическое изменение напряжения (импульсы напряжения). Нижний уровень напряжения подбирается так, чтобы осаждался только один металл („первый“, с меньшим потенциалом осаждения) - при этом в поре растет слой соответствующего состава. При повышении потенциала выше определенного значения начинает осаждаться и „второй“ металл - т.е. будут выделяться уже оба металла. В принципе гальванический осадок при этом содержит оба металла и является двухкомпонентным. Однако содержание „первого“ металла можно минимизировать за счет уменьшения его концентрации в ростовом растворе. („Платой“ за это будет соответствующее увеличение времени осаждения слоев из этого металла). В целом толщина каждого слоя при этом будет зависеть и от состава электролита, и от времени осаждения. Описанный выше способ называется „однованновым“ (,single-bath“), поскольку используется один тип электролита (многокомпонентный) и одна ванна, в которой и проводится весь процесс. Другим подходом является так называемый „двухванновый“ („double-bath“), когда для осаждения каждого металла используется своя ячейка (ванна), то есть для двухкомпонентных НП их две. В ходе процесса образец перемещается из одного электролита в другой. Преимущество такого метода (исторически для формирования покрытий он был применен первым) состоит в том, что слои получаются более чистыми, без примеси других металлов. Недостатком является необходимость смены электролита, которая приводит к возможности образования на границе раздела слоев окислов или загрязнений. В настоящее время применяются оба метода получения слоевых структур, однако однованновый используется гораздо шире.
Слоевые НП проявляют ряд уникальных особенностей. Одна из них - эффект гигантского магнетосопротивления (ГМС), который был обнаружен практически сразу после получения таких НП. Авторами работы [10] были синтезированы НП с чередованием $\mathrm{Co} / \mathrm{Cu}$ в сорока нанометровых порах поликарбонатной трековой мембраны. Толщина чередующихся слоев была около $10 \mathrm{~nm}$, а величина эффекта ГМС составляла 15\%. В [11] были получены слоевые НП $(\mathrm{Co} / \mathrm{Cu}$ и $\mathrm{FeNi} / \mathrm{Cu})$ и для них также наблюдался эффект ГМС. В [12] эффект ГМС был исследован для НП с чередующимися слоями различной толщины. Было обнаружено сильное влияние толщины слоев на величину эффекта ГМС. В частности, авторы показали, что эффект не наблюдается, когда толщина слоев превышает определенный размер. В работе [13] было также показано, что диаметр слоевых НП несколько превосходит диаметр ростовых каналов пор - это объяснялось расширением растущих металлических НП в поре из эластичного полимера. Авторы [14] синтезировали слоевые $\mathrm{Co} / \mathrm{Cu}$ НП двумя методами - однованновым и двухванновым. Было установлено, что в образцах НП, полученных однованновым методом, эффект ГМС имеет большее значение. Это означает, что примесь меди в кобальтовом слое не приводит, как ожидалось, к подавлению эффекта.

В ряде работ рассмотрены другие особенности и потенциальные применения слоевых НП. Например, в работах $[15,16]$ исследованы особенности формирования и движения вихревых доменных стенок в НП, состоящих из периодических слоев $\mathrm{Co} / \mathrm{Ni}$. Показано, что движением доменных стенок, можно управлять спинполяризованным током. При этом интерфейсы между слоями никеля и кобальта создают периодическую структуру из энергетических барьеров, которые „пиннингуют“ движение доменных стенок. Показано, что на этот процесс оказывает влияние и внешнее магнитное поле. Авторы считают, что на основе таких структур возможно создание магнитной памяти с более высокой плотностью записи. Помимо этого, в ряде других работ рассмотрены возможности использования слоевых НП в качестве „микромагнитов“, сенсоров различных типов и некоторые другие применения. Отметим, что перспективность использования именно магнитных свойств НП была отмечена в одной из первых работ по получению НП [17]. Все вышеперечисленное говорит о перспективности получения и исследования различных типов слоевых НП.

В большинстве работ, посвященных синтезу и исследованию слоевых НП, рост НП проводится в матрице из пористого оксида алюминия. Однако используемые в нашей работе полимерные трековые мембраны обладают и другими достоинствами - в частности, гибкостью (откуда вытекает перспектива их использования в так называемой „гибкой электронике“). Вместе с тем, анализ литературы указывает на то, что особенности получения слоевых НП в порах трековых мембран изучены мало. Представляет интерес и связь условий получения со 
структурой и свойствами получаемых массивов слоевых НП.

В связи с этим целью настоящей работы является изучение возможностей управления структурой слоевых НП на стадии электроосаждения. Другой целью является изучение влияния структуры на магнитные свойства, в том числе с учетом взаимодействия отдельных НП. Отметим, что последняя задача напрямую связана с давно решаемой задачей об использовании массивов НП для магнитной записи с высокой плотностью.

\section{2. Материалы и методы}

\section{1. Матрицы и гальваническое осаждение}

В настоящей работе в качестве ростовых матриц (темплатов) были использованы полимерные трековые мембраны производства ОИЯИ (г. Дубна, Россия). Матрицы имели следующие параметры: полимерная пленка ПЭТФ толщиной $12 \mu \mathrm{m}$, поры с диаметрами $100 \mathrm{~nm}$ и $70 \mathrm{~nm}$ и поверхностной плотностью $10^{9}$ и $1.2 \cdot 10^{9}$ пор на $\mathrm{cm}^{2}$. На поверхность матрицы наносился тонкий электропроводящий слой. Слой наносился методом термического распыления металла (обычно меди) в вакууме (установка ВУП-4). Заготовки необходимых размеров помещались в гальваническую ячейку, в которой и проводилось осаждение металла (металлов) в поры. Ячейка (конструкции СКБ ИК РАН) имела следующие параметры: площадь получаемого образца $-2.5 \mathrm{~cm}^{2}$; объем ростовой камеры - $30 \mathrm{~mL}$, площадь анода составляла $7 \mathrm{~cm}^{2}$.

В настоящей работе были получены слоевые нанопроволоки двух типов - $\mathrm{Cu} / \mathrm{Ni}$ и $\mathrm{Cu} / \mathrm{Co}$.

Для электроосаждения использовались специальные электролиты следующего состава. В случае осаждения $\mathrm{H \Pi} \mathrm{Cu} / \mathrm{Ni}: \mathrm{NiSO}_{4} \times 7 \mathrm{H}_{2} \mathrm{O}-196.7 \mathrm{~g} / \mathrm{L} ; \mathrm{CuSO}_{4} \times 5 \mathrm{H}_{2} \mathrm{O}-$ $6.25 \mathrm{~g} / \mathrm{L} ; \mathrm{H}_{3} \mathrm{BO}_{3}-31.6 \mathrm{~g} / \mathrm{L}$. В случае осаждения НП $\mathrm{Cu} / \mathrm{Co}: \mathrm{CoSO}_{4} \times 7 \mathrm{H}_{2} \mathrm{O}-200 \mathrm{~g} / \mathrm{L} ; \mathrm{CuSO}_{4} \times 5 \mathrm{H}_{2} \mathrm{O}-$ $8 \mathrm{~g} / \mathrm{L} ; \mathrm{H}_{3} \mathrm{BO}_{3}-40 \mathrm{~g} / \mathrm{L}$. Для задания режима осаждения был использован программируемый источник Elins P-2X с возможностью задавать сложные режимы электроосаждения (изменения потенциала в зависимости от времени, протекшего заряда). Осаждение проводилось при потенциалах, лежащих в пределах от 0.5 до $1.8 \mathrm{~V}$, задаваемых с помощью программы источника. Длительность импульсов напряжения варьировалась в пределах от 1 до 300 s. Выбор режима осаждения был одним из этапов работы. Выбранные в работе режимы описаны в разделе „Результаты“.

Полученные массивы НП в ряде последующих экспериментов исследовались непосредственно в ростовой матрице - методами магнитометрии и рентгеноструктурного анализа. Для микроскопических исследований нанопроволоки отделялись от ростовой матрицы. Процесс проводился в растворе концентрированной щелочи $(5 \mathrm{~N} \mathrm{NaOH}) 50^{\circ} \mathrm{C}$, в течении $2-3 \mathrm{~h}$, с последующей промывкой в дистиллированной воде. Отметим, что для исследований с помощью растровой электронной микроскопии (РЭМ) НП готовились в виде массива на общем основании (слой меди), в то время как для исследований методом просвечивающей электронной микроскопии (ПЭМ) была получена взвесь НП, из которой после диспергирования в ультразвуковой ванне, НП помещали на специальные медные сетки с углеродной подложкой.

Особой задачей было приготовление образцов для магнитно-силовой микроскопии (МСM). Для исследования проволоки должны быть расположены горизонтально и закреплены на плоской подложке. Использовались три различных способа приготовления таких образцов. В первом НП фиксировались на поверхности проводящего скотча. В других нанопроволоки помещались на поверхность полимерной пленки-держателя. При этом во втором случае НП удерживались на поверхности только за счет адгезии, а в третьем случае проводилось дополнительное запыление тонким слоем меди. Сравнение полученных результатов дано в разделе „Результаты“.

\section{2. Микроскопия}

На первом этапе для оценки и предварительного исследования образцов использовался оптический микроскоп АЛЬТАМИ. На следующем этапе - для оценки поверхности и элементного состава - применялся растровый микроскоп (РЭМ) JEOLltd., JCM-6000plus, (ускоряющее напряжение $15 \mathrm{kV}$ ) с приставкой для микроанализа.

Структурные исследования выполнены методами растровой электронной микроскопии (РЭМ), просвечивающей электронной микроскопии (ПЭМ), высокоразрешающей электронной микроскопии (ВРЭМ), просвечивающей растровой электронной микроскопии (ПРЭМ), электронной дифракции и энергодисперсионного анализа. Использовался микроскоп FEI TecnaiOsiris с ускоряющим напряжением $200 \mathrm{kV}$. Элементный анализ проведен с помощью специальной системы SuperX EDS, включающей в себя четыре кремниевых детектора, конструкция которой позволяет получать большие по площади карты распределения химических элементов за несколько минут. Для обработки и анализа изображений и электронограмм, полученных в электронном микроскопе, использовались программы DigitalMicrograph, Esprit, TIA, JEMS.

\section{3. Рентгеноструктурный анализ}

Исследование образцов проводилось на дифрактометре RIGAKU Miniflex 600. Использовался медный анод (длина волны характеристического излучения $\lambda=1.542 \AA$ ), применялся режим с ускоряющим напряжением $40 \mathrm{kV}$ при токе $15 \mathrm{~mA}$. Измерения проводились в интервале углов $40-80^{\circ}$. При измерениях и обработке результатов использовались стандартные методы. Линии меди от подложки (которые были очень сильными 
практически во всех образцах) в ряде случаев использовались для дополнительной калибровки: спектр мог быть сдвинут из-за деформации и/или неровности приклейки тонкой пленки к держателю.

\section{4. Магнитные измерения образцов}

Для изучения магнитных характеристик образцов применялись методы магнитно-силовой микроскопии и вибрационной магнитометрии.

М аг н и т о м е т и я. Измерения кривых намагничивания образцов проводились при комнатной температуре на экспериментальном магнитометре, принцип работы и основные узлы которого описаны в патенте РФ [18]. В отличие от других магнитометров вибрационного типа, данный прибор позволяет одновременно регистрировать зависимости как наведенного, так и остаточного магнитного момента в образце от величины приложенного магнитного поля вплоть до $500 \mathrm{mT}$.

Магнитно-силовая микроскопия (М С M). Отметим, что ранее авторы применяли метод МСМ для исследования ферромагнитных НП, находящихся в полимерной матрице; при этом сканирование проводилось вдоль плоскости матрицы и фиксировалось магнитное состояние концов НП [19]. В настоящей работе для отдельно лежащих (горизонтальных) НП изучалось магнитное состояние вдоль оси проволоки. Исследования горизонтальных НП проводились с помощью сканирующего зондового микроскопа (С3М) Solver P47 Pro, работающего в режиме атомно-силовой и магнитносиловой микроскопии (АСМ и МСМ). При этом АСМ служит для получения топографии поверхности проволок. МСМ используется для получения распределения намагниченности в проволоках. Исследование одной и той же области различными кантилеверами оказалось невозможным, поэтому АСМ- и МСМ-измерения проводились сразу одним магнитным зондом. Последнее приводило к большой свертке на АСМ-изображении проволок из-за магнитного напыления на кончике зонда. Для ACM- и МСМ-измерений использовались стандартные коммерческие кантилеверы Multi75M-G (BudgetSensor). Во время МСМ измерений использовалась однопроходная методика, при которой МСМ-зонд перемещается над поверхностью образца на достаточном удалении (несколько десятков нанометров) для того, чтобы исключить перемагничивание слоев проволоки магнитным полем зонда. Для проведения МСМ-измерений во внешнем магнитном поле в СЗМ был установлен электромагнит, позволяющий изменять величину внешнего магнитного поля в плоскости образца в интервале от -16 до +16 mТ с шагом $0.5 \mathrm{mT}$.

\section{3. Результаты}

\section{1. Подбор режимов осаждения слоев никеля/меди и кобальта/меди}

Одной из задач при получении слоевых НП является, как уже говорилось, подбор напряжений, соот-

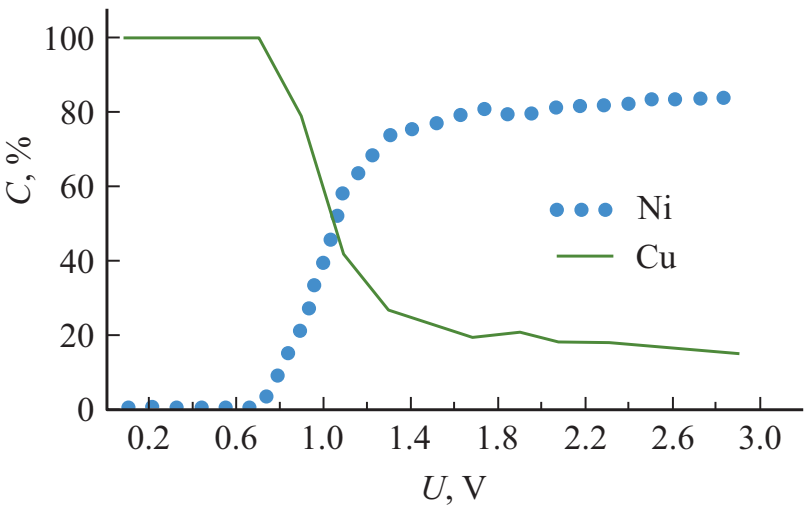

Рис. 1. Зависимость состава от ростового напряжения.

ветствующих оптимальному росту слоя для каждого металла. В этой связи на первом этапе была проделана поисковая работа по осаждению медно-никелевых НП при различных напряжениях. Использовался стандартный ростовой электролит, включающий ионы обоих металлов, а осаждение велось на плоскую поверхность. Была получена серия образцов, при одном напряжении каждый. Ростовое напряжение изменялось от 0.2 до $3 \mathrm{~V} \mathrm{c}$ шагом $0.2 \mathrm{~V}$. Синтезированные образцы исследовались с помощью РЭМ - оценивалось качество поверхности и элементный состав. Полученные данные по зависимости элементного состава от ростового напряжения приведены на рис. 1.

Представленные зависимости позволяют выбрать оптимальные режимы для осаждения меди и никеля - 0.7 и $1.8 \mathrm{~V}$ соответственно. При напряжении менее $0.6 \mathrm{~V}$ не растет ни один из металлов, при напряжениях от 0.6 до $1.4 \mathrm{~V}$ растет медь, значительное количество никеля осаждается при напряжениях более $1.6 \mathrm{~V}$. Дальнейший же рост напряжения не приводит к изменению соотношения элементов, однако приводит к ускорению роста. Последнее приводит к заметному ухудшению качества поверхности, наблюдаемому на микрофотографиях.

Аналогичные эксперименты были проведены при осаждении кобальта и меди. В этом случае ростовые напряжения были определены как $0.5 \mathrm{~V}$ для меди и $1.5 \mathrm{~V}$ для кобальта. Полученные параметры были использованы на следующих этапах для гальванического осаждения чередующихся слоев $(\mathrm{Ni} / \mathrm{Cu}$ или $\mathrm{Co} / \mathrm{Cu})$ в поры матрицы.

\section{2. Предварительные исследования}

После синтеза образцы были исследованы на оптическом микроскопе для выявления дефектных областей (например, так называемые „перероста“). Другим способом контроля был рентгеноструктурный анализ, показавший наличие в образцах соответствующих металлов. Так, пики меди несли мало информации, так называемую основную часть интенсивности давала достаточно толстая гальванически нанесенная медная подложка. В то же время пики никеля (или кобальта) были индицированы и позволили сделать предварительный вывод 
о наличии этих металлов в составе НП и о фазовом составе.

\section{3. Электроосаждение и ПЭМ слоевых $\mathrm{H} \Pi \mathrm{Ni} / \mathrm{Cu}$}

Работа по получению слоевых НП проводилась с использованием матриц с диаметрами пор 70 и $100 \mathrm{~nm}$. Контроль полученных образцов проводился (после их отделения от ростовой матрицы) методом ПЭМ.

На первом этапе исследования проводилось электрохимическое осаждение в поры трековых мембран с диаметром $100 \mathrm{~nm}$. При этом потенциал изменялся в зависимости от времени (время осаждения для последовательно растущих слоев было постоянным). После осаждения матрица удалялась, а образцы исследовались с помощью ПЭМ. Полученные результаты представлены на рис. 2.

Видно, что слои имеют различную толщину. Кроме того, толщины слоев изменяются по мере роста НП (от 50 до $100 \mathrm{~nm}$ ). Также стоит отметить, что некоторые слои не перпендикулярны оси НП, имеются „затекания“ одного слоя в другой с сохранением точной границы слоев.

Для получения НП со слоями одинаковой толщины был предложен другой метод контроля количества осажденного металла. Длительность импульсов в последовательности не была одинаковой. Время осаждения одного слоя увеличивалось по мере заполнения матрицы. В качестве критерия, определяющего длительность, был выбран протекший заряд (известно, что в соответствии с законом Фарадея именно протекший заряд определяет количество осажденного металла). Заряд в данном случае рассчитывался теоретически. ПЭМ-изображения НП, полученных в этом режиме, представлены на рис. 3.

Видно, что слои в НП, полученных в данном режиме, не изменяются по толщине $(30 \mathrm{~nm})$ и равны друг другу. В следующей серии экспериментов ставилась задача уменьшения толщины слоев. Попытка решить данную задачу была предпринята для НП диаметром $70 \mathrm{~nm}$. Предполагалось получить НП с толщиной слоев $10 \mathrm{~nm}$. На данном этапе, как и на предыдущем, использовался метод контроля протекшего заряда. Результаты ПЭМ синтезированных НП представлены на рис. 4.

Анализ полученных результатов показывает, что попытки уменьшить толщину слоев были успешными до толщин $10-15 \mathrm{~nm}$. При дальнейшем уменьшении толщины слоев происходит сглаживание (выравнивание) концентраций. Изображение НП и распределение элементов вдоль оси НП представлены на рис. 5.

Видно, что в соседних слоях происходит уменьшение различия концентраций элементов: концентрации меди в никелевом слое - от 27 до 45\%, а концентрации никеля в медном слое - от 32 до 45\%. (Отметим, что в предыдущих образцах слой меди содержал лишь небольшую примесь никеля $(2-3 \%)$, а слой никеля содержал порядка $20 \%$ меди). При этом есть звенья,
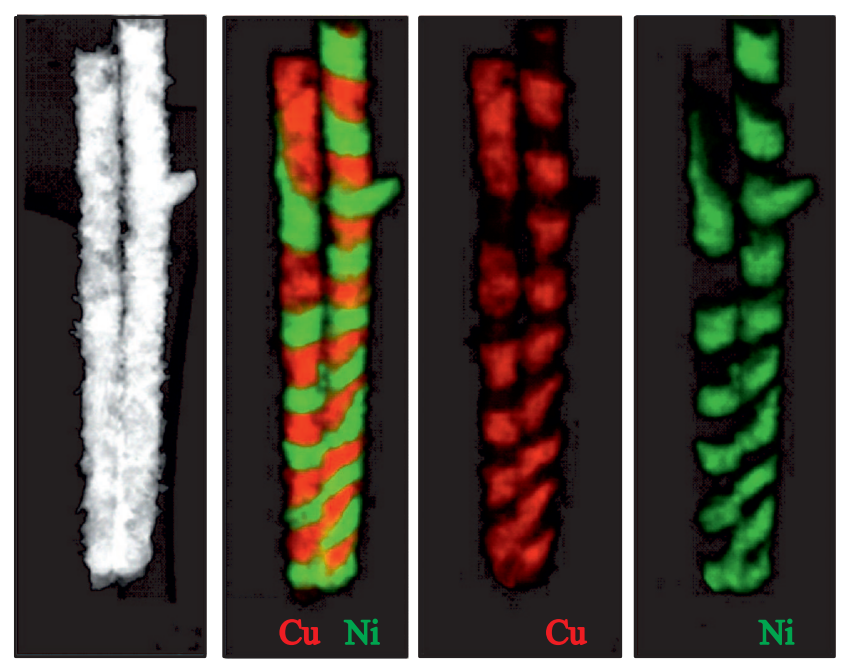

$-100 \mathrm{~nm}$

$-100 \mathrm{~nm}$

$-100 \mathrm{~nm}$

Рис. 2. ПРЭМ-изображение с $z$-контрастом и карты распределения химических элементов образцов слоевых $\mathrm{HП} \mathrm{Ni} / \mathrm{Cu}$, полученных при импульсах равной длительности.

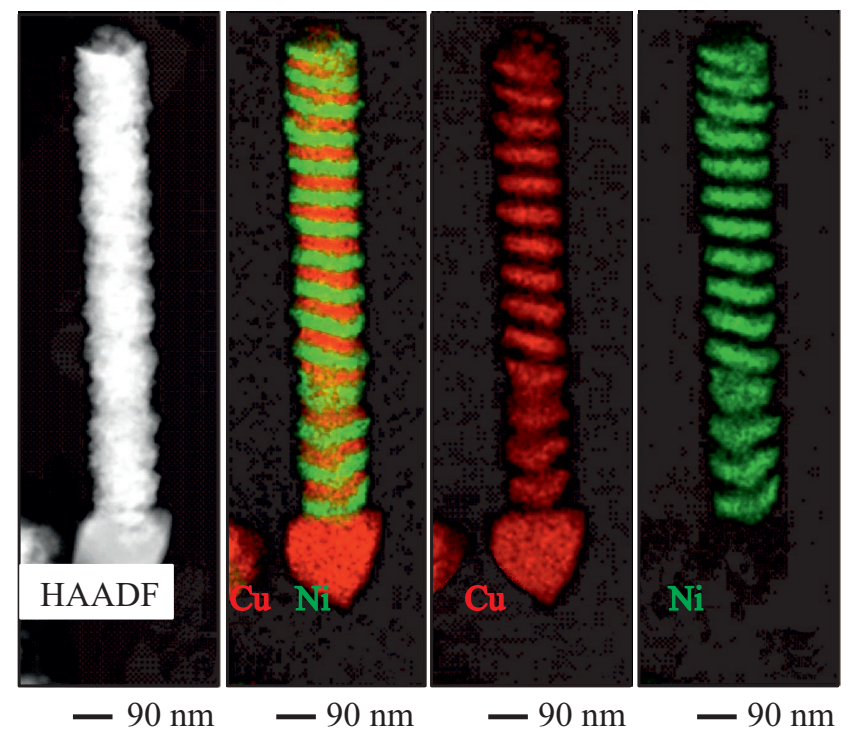

Рис. 3. ПРЭМ-изображение с $z$-контрастом и карты распре-

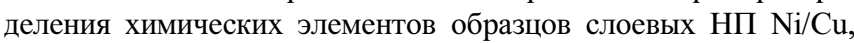
полученных при импульсах с равным протекшим зарядом.

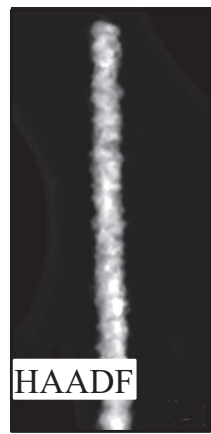

$-80 \mathrm{~nm}$

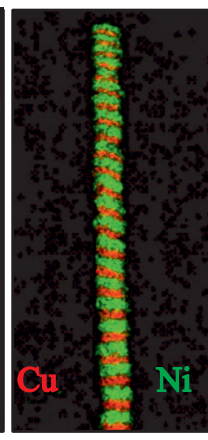

$-80 \mathrm{~nm}$

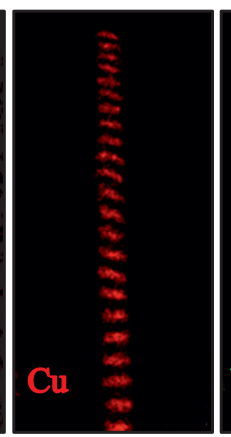

$-80 \mathrm{~nm}$

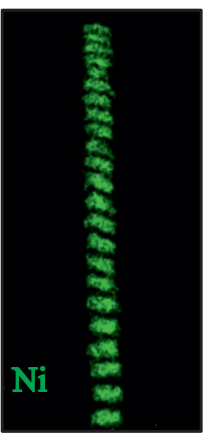

$-80 \mathrm{~nm}$
Рис. 4. ПРЭМ-изображение с $z$-контрастом и карты распре-

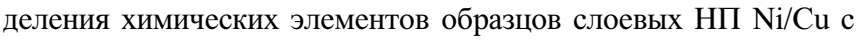
толщиной отдельных слоев $10 \mathrm{~nm}$. 
$-70 \mathrm{~nm}$

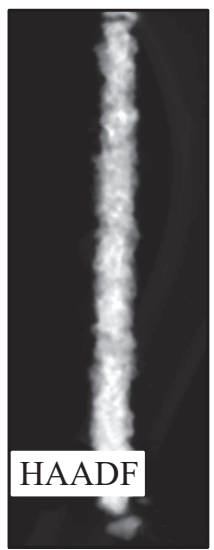

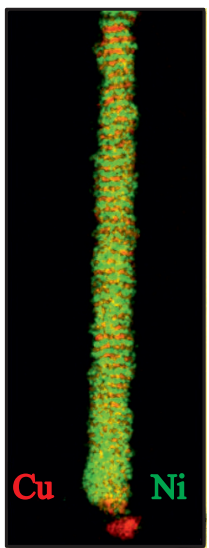

$-70 \mathrm{~nm}$

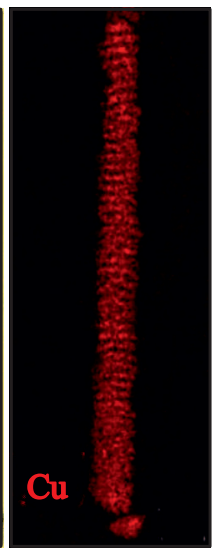

$-70 \mathrm{~nm}$

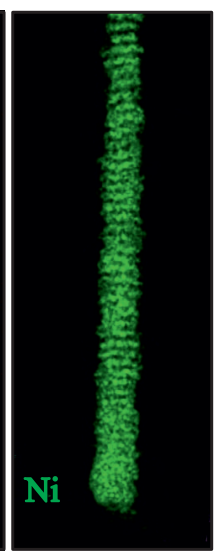

$-70 \mathrm{~nm}$
Рис. 5. ПРЭМ-изображение с $z$-контрастом и карты распреде-

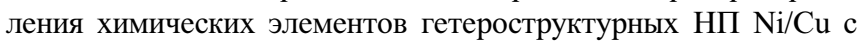
толщиной отдельных слоев менее $10 \mathrm{~nm}$.

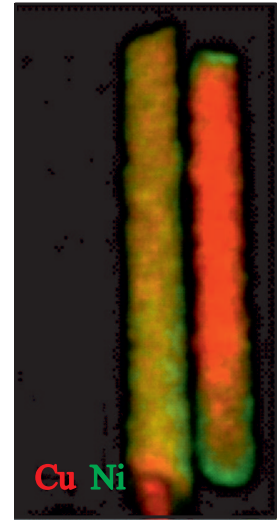

$200 \mathrm{~nm}$

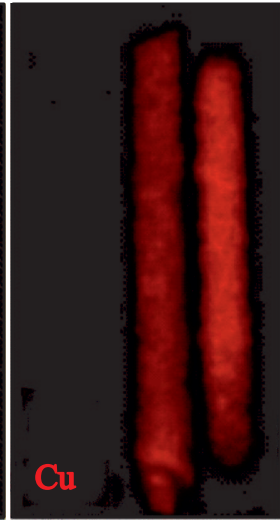

$200 \mathrm{~nm}$

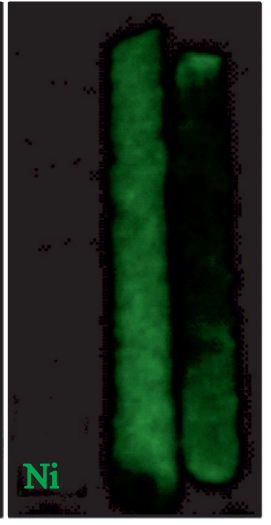

$200 \mathrm{~nm}$
Pис. 6. Пример стержень-оболочка структуры: оболочка из никеля „охватывает“ сердцевину из меди.

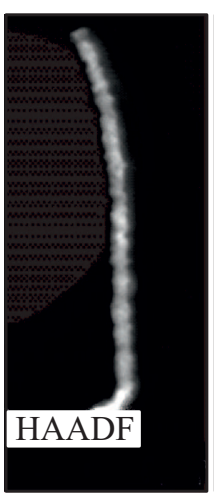

$-100 \mathrm{~nm}$

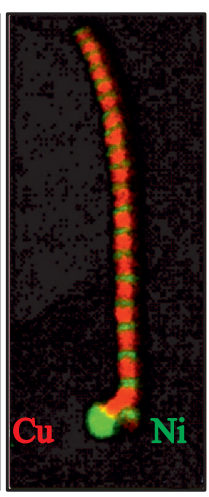

$-100 \mathrm{~nm}$

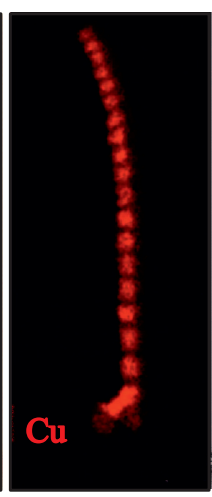

$-100 \mathrm{~nm}$

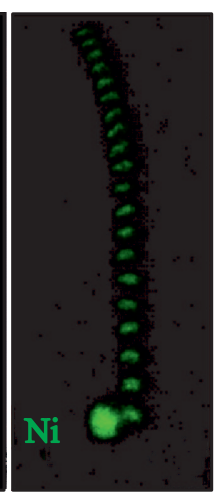

$-100 \mathrm{~nm}$
Рис. 7. ПРЭМ-изображение с $z$-контрастом и карты распределения химических элементов образцов, полученных в режиме с паузами между импульсами напряжения.

где концентрация элементов практически одинаковая. Очевидно, в этом случае кристаллиты представляют собой твердый раствор металлов.
В отдельных случаях при снижении толщины слоя чередование металлов вдоль оси НП прекращалось, образовывались структуры типа (стержень-оболочка; в этом случае „рубашка“ из никеля окружает сердечник из меди). Пример приведен на рис. 6.

Можно предположить, что причина возникновения таких структур связана с особенностями диффузии различных ионов в условиях ограниченной геометрии и времени (узкий поровый канал, малое время осаждения и малая длительность импульса). Выяснение причин данного явления требует дальнейшего исследования.

Для улучшения качества тонких слоев была предпринята попытка „выравнивания“ процесса электроосаждения. Предполагалось, что при достаточно быстром росте происходит истощение электролита вблизи поверхности растущего металла. Для устранения этого явления в последовательность чередования импульсов были добавлены паузы (выключение напряжения). Предполагалось, что в этот момент происходит выравнивание концентрации ионов вблизи рабочего электрода. ПЭМизображения полученных в этом случае слоевых НП представлены на рис. 7.

По результатам видно, что примененный режим (паузы после осаждения слоя никеля) приводят к результату, отличному от ожидаемого: к резкому изменению соотношения толщин слоев (слой никеля в $2-2.5$ раза меньше слоя меди). Можно предположить, что это вызвано тем, что во время паузы происходит растворение слоя никеля, одновременно происходит диффузия ионов меди к растущей поверхности. Это приводит к увеличению относительной толщины следующего слоя меди.

\section{4. Электроосаждение и ПЭМ слоевых $\mathrm{H} \Pi \mathrm{Co} / \mathrm{Cu}$}

Аналогично НП из $\mathrm{Ni} / \mathrm{Cu}$ в матрице с порами диаметром $100 \mathrm{~nm}$ были получены образцы гетероструктурных НП, состоящих из чередующихся слоев кобальта и меди. В этой части работы периодичность изменения

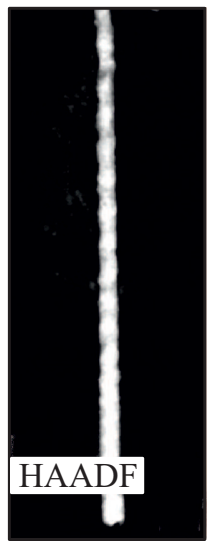

$-300 \mathrm{~nm}$

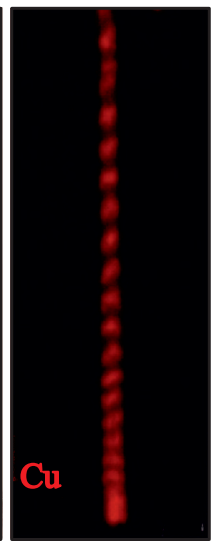

$-300 \mathrm{~nm}$

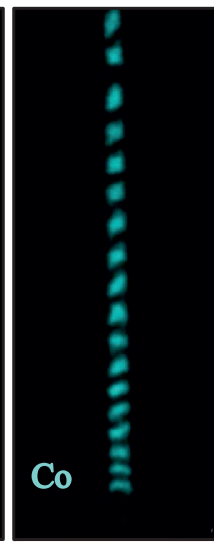

$-300 \mathrm{~nm}$

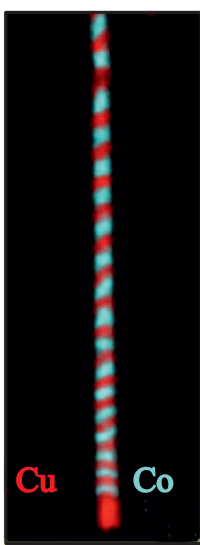

$-300 \mathrm{~nm}$
Рис. 8. ПРЭМ-изображение с $z$-контрастом и карты распределения химических элементов образцов слоевых $\mathrm{HП} \mathrm{Co} / \mathrm{Cu}$. 

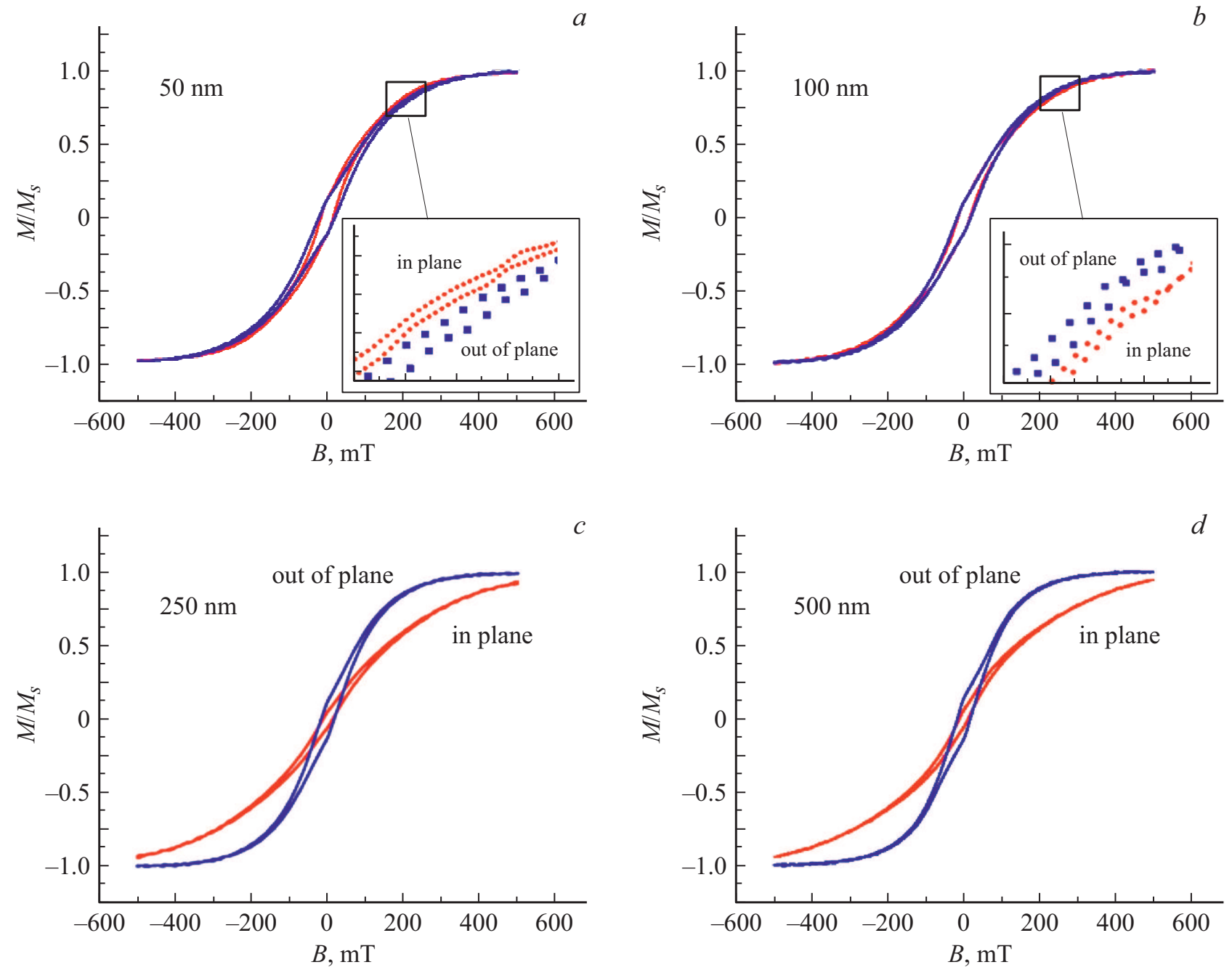

Рис. 9. Кривые гистерезиса намагниченности массивов слоевых НП с чередованием $\mathrm{Co} / \mathrm{Cu}$ при различной толщине чередующихся слоев: $a-50, b-100, c-250$ и $d-500 \mathrm{~nm}$. Здесь кривые „in-plane“ и „out-of-plane“ соответствуют двум предельным ориентациям магнитного поля по отношению к плоскости трековой мембраны.

напряжения также определялась протекшим зарядом, который рассчитывался теоретически, исходя из требуемой толщины слоев. В первых экспериментах желательная толщина слоя составляла $100 \mathrm{~nm}$. Результаты ПЭМ-исследования полученных образцов слоевых НП представлены на рис. 8.

Приведенные изображения свидетельствуют о том, что получены НП с четким чередованием слоев различных металлов. Вместе с тем видно, что толщина слоев изменяется вдоль оси НП. Отметим и одновременное изменение диаметра полученных НП. Можно предположить, что эти процессы связаны. Однако, для выяснения причины этого необычного поведения необходимы дополнительные исследования.

\section{5. Магнитометрия}

Проводилась магнитометрия массивов слоевых НП как в ,in-plane“, так и в „out-of-plane“ геометриях по отношению к плоскости полимерной мембраны, что соответствует направлениям магнитного поля перпендикулярно и параллельно нанопроволокам, соответственно. Поскольку диаметр НП составляет $\sim 100 \mathrm{~nm}$, для магнитных измерений были взяты образцы НП с толщиной чередующихся слоев 50, 100, 250 и $500 \mathrm{~nm}$. Это позволило сравнить случаи, когда аспектное отношение толщины слоя НП к ее диаметру меньше, равно либо больше единицы. Результаты измерений для массива НП с чередованием $\mathrm{Co} / \mathrm{Cu}$ представлены на рис. 9 .

Из представленных на рисунке магнитных кривых (петель магнитного гистерезиса) следует, что НП со слоями $\mathrm{Co} / \mathrm{Cu}$ толщиной 50 и $100 \mathrm{~nm}$ (аспектное отношение равно 0.5 и 1 соответственно) намагничиваются похожим образом при сканировании внешнеим магнитным полем как параллельно, так и перпендикулярно оси НП (см. рис. 9, $a$ и $b$ ). Отметим, что небольшое различие все же есть: в НП со слоями толщиной $50 \mathrm{~nm}$ намагниченность в геометрии ,іn-plane“ выходит 

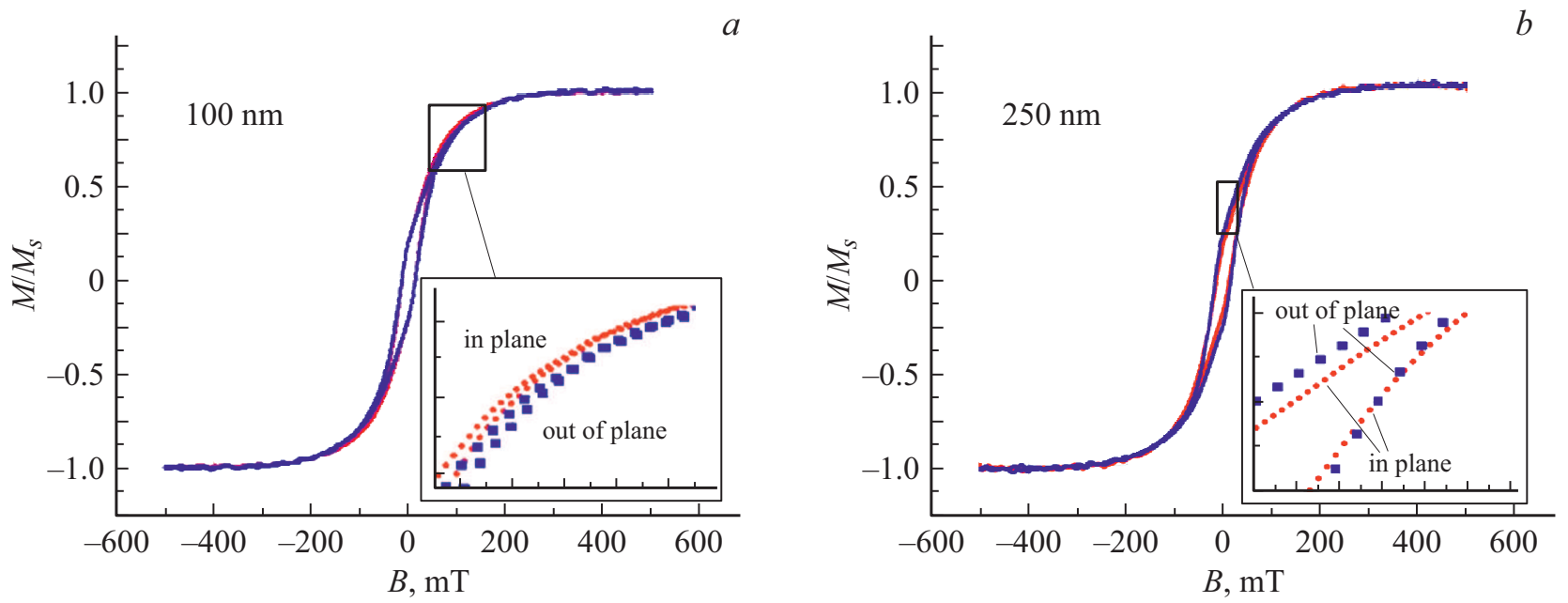

Рис. 10. Кривые гистерезиса намагниченности массивов слоевых НП с чередованием $\mathrm{Ni} / \mathrm{Cu}$ при толщине чередующихся слоев 100 и $250 \mathrm{~nm}$.

на насыщение несколько быстрее, чем в геометрии „out-of-plane“. Картина резко меняется при увеличении аспектного отношения до 2.5 и 5.0 (см. рис. 9, $c$ и $d$ ). Намагниченность вдоль оси НП, то есть, в геометрии „out-of-plane“, выходит на насыщение при заметно меньшем значении магнитного поля, чем в геометрии измерения „in-plane“. Другими словами, анизотропия формы отдельно взятого слоя в НП оказывает доминирующее влияние на магнитное поведение массива слоевых НП в целом. Более того, с увеличением аспектного отношения прослеживается тенденция к росту величины остаточной намагниченности вдоль НП, и уменьшение этой величины в перпендикулярном направлении (табл. 1).

Таблица 1. Относительные значения остаточной намагниченности массивов НП с чередованием слоев $\mathrm{Co} / \mathrm{Cu}$

\begin{tabular}{c|c|c}
\hline $\begin{array}{c}\text { Толщина слоя, } \\
\mathrm{nm}\end{array}$ & $\begin{array}{c}\text { Отн. остаточная } \\
\text { намагниченность } \\
\text {,in-plane“, } M_{R} / M_{S}\end{array}$ & $\begin{array}{c}\text { Отн. остаточная } \\
\text { намагниченность } \\
\text {,out-of-plane“, } M_{R} / M_{S}\end{array}$ \\
\hline 50 & 0.12 & 0.12 \\
100 & 0.10 & 0.11 \\
250 & 0.05 & 0.13 \\
500 & 0.06 & 0.14
\end{tabular}

Таблица 2. Значения коэрцитивных полей для НП с чередованием слоев $\mathrm{Co} / \mathrm{Cu}$

\begin{tabular}{c|c}
\hline Толщина слоя, $\mathrm{nm}$ & $H_{K}, \mathrm{mT}$ \\
\hline 50 & 20.9 \\
100 & 17.2 \\
250 & 17.0 \\
500 & 17.1
\end{tabular}

Таблица 3. Относительные значения остаточной намагниченности массивов НП с чередованием слоев $\mathrm{Ni} / \mathrm{Cu}$

\begin{tabular}{c|c|c}
\hline $\begin{array}{c}\text { Толщина слоя, } \\
\mathrm{nm}\end{array}$ & $\begin{array}{c}\text { Отн. остаточная } \\
\text { намагниченность } \\
\text {,in-plane“, } M_{R} / M_{S}\end{array}$ & $\begin{array}{c}\text { Отн. остаточная } \\
\text { намагниченность } \\
\text {,out-of-plane“, } M_{R} / M_{S}\end{array}$ \\
\hline 100 & 0.19 & 0.20 \\
250 & 0.17 & 0.24
\end{tabular}

Таблица 4. Значения коэрцитивных полей для НП с чередованием слоев $\mathrm{Ni} / \mathrm{Cu}$

\begin{tabular}{c|c}
\hline Толщина слоя, $\mathrm{nm}$ & $H_{K}, \mathrm{mT}$ \\
\hline 50 & 12.7 \\
100 & 13.3 \\
250 & 15.5 \\
500 & 14.5
\end{tabular}

Также стоит отметить, что коэрцитивная сила (в геометрии „out-of-plane“) для слоев толщиной $100-500 \mathrm{~nm}$ меняется на уровне погрешности, однако для НП со слоями толщиной $50 \mathrm{~nm}$ заметно больше (табл. 2).

$\mathrm{B}$ образцах с чередованием $\mathrm{Ni} / \mathrm{Cu}$ таких изменений не наблюдается (рис. 10).

В данном случае при переходе от толщины слоев НП, равной 100 к $250 \mathrm{~nm}$ поле анизотропии меняется незначительно, однако значительно изменяется отношение остаточных намагниченностей в геометриях „out-ofplane“и „in-plane“ (табл. 3).

Коэрцитивные поля для никелевых образцов изменяются немонотонно, однако наблюдается увеличение данного параметра с увеличением аспектного отношения толщины слоя к диаметру НП (табл. 4). 

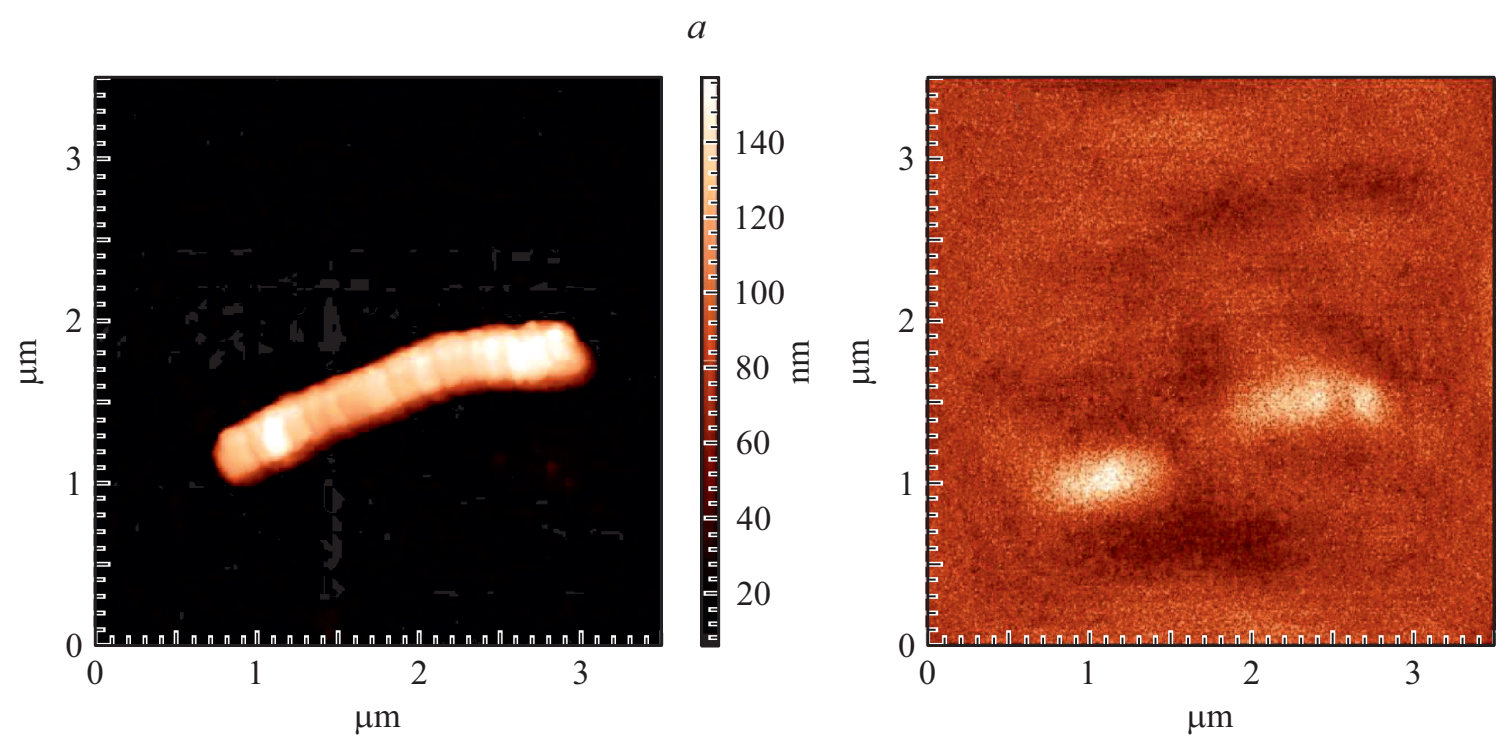

$b$

Рис. 11. $\mathrm{ACM}(a)$ и $\mathrm{MCM}(b)$ изображение отдельной проволоки $\mathrm{Ni} / \mathrm{Cu}$ в отсутствие внешнего магнитного поля.

$a$

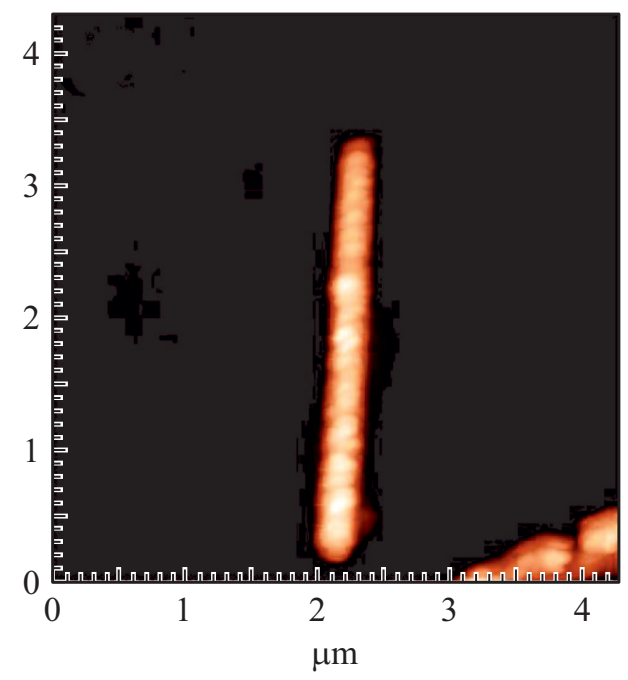

$a$

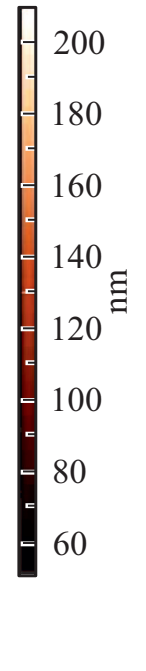

$b$

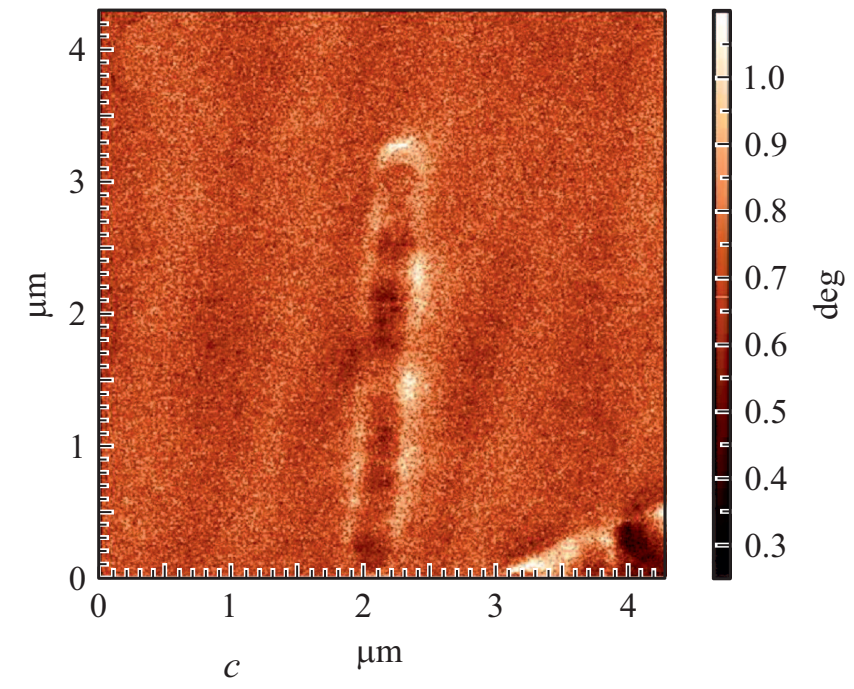

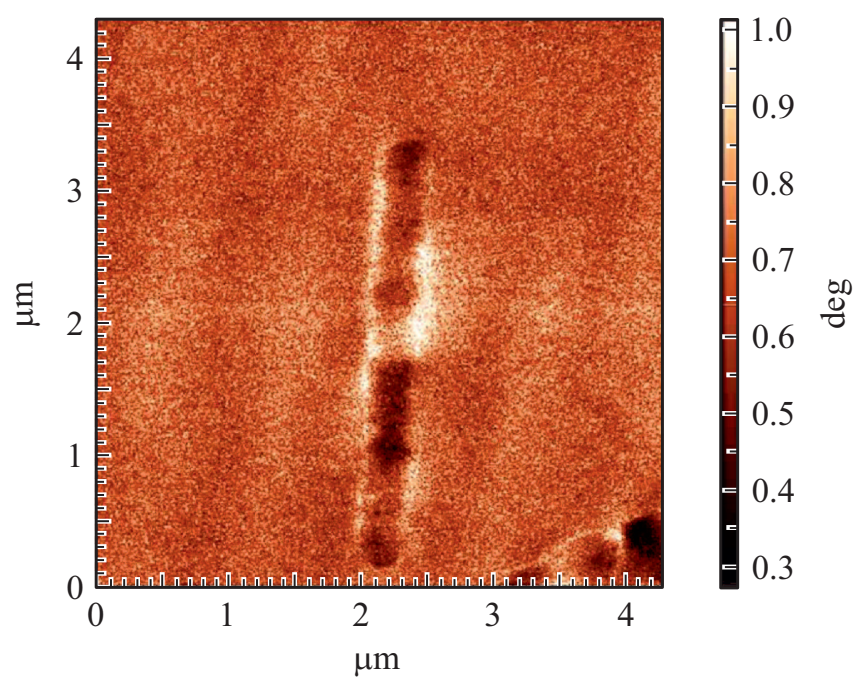

Рис. 12. (a) - АСМ-изображение отдельной проволоки $\mathrm{Ni} / \mathrm{Cu}$ диаметром около $140 \mathrm{~nm} ;(b)$ и $(c)-\mathrm{MCM}$-изображения проволоки во внешнем магнитном поле величиной $+16 \mathrm{mT}$ и $-16 \mathrm{mT}$ соответственно. 
$a$
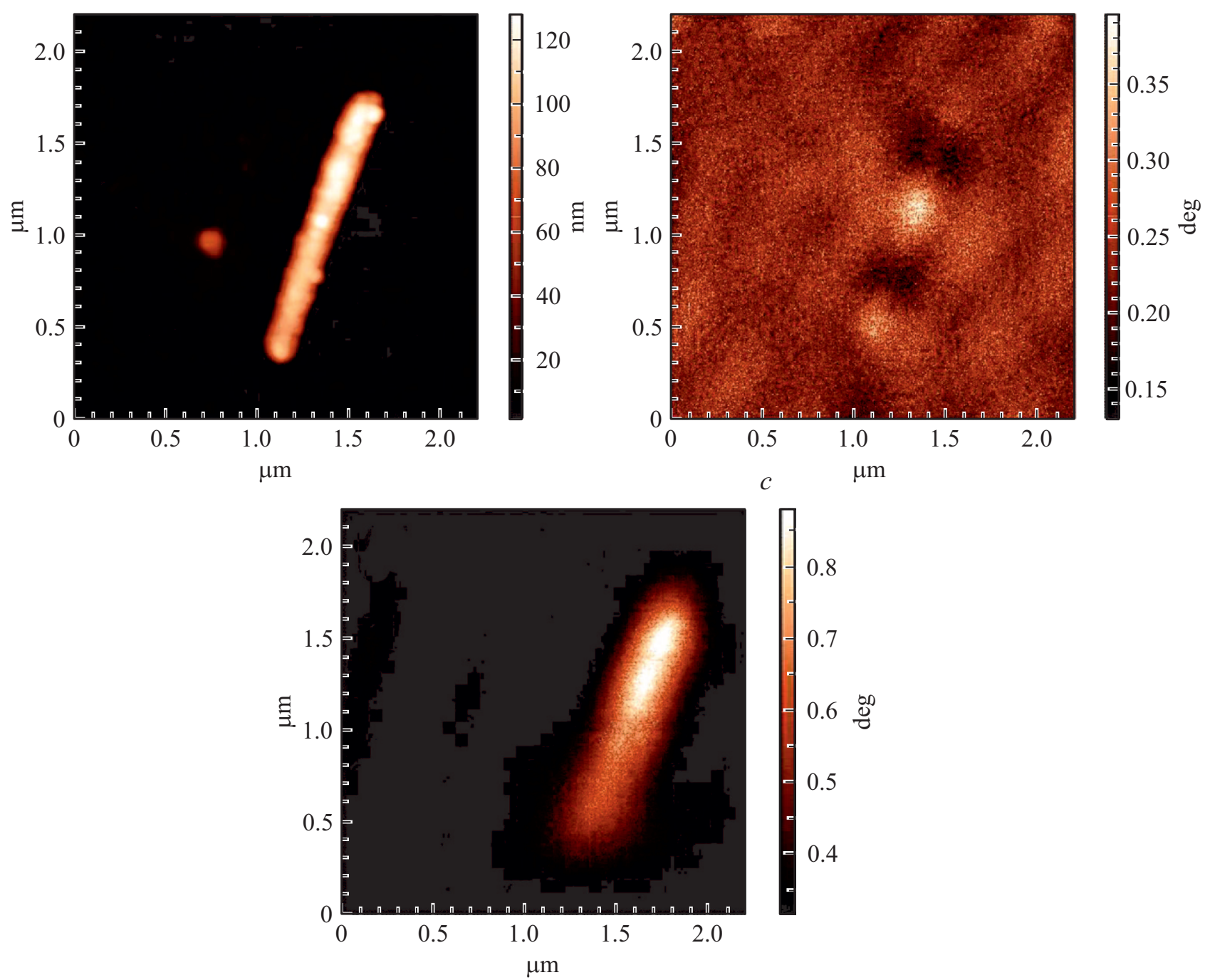

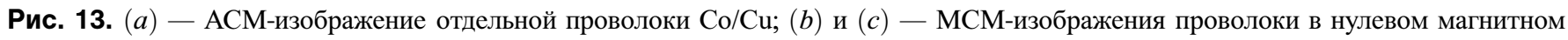
поле и во внешнем магнитном поле величиной $+16 \mathrm{mT}$.

\section{6. Магнитно-силовая микроскопия}

Для МСМ-исследований был выбран следующий способ закрепления единичных НП на плоской поверхности. НП должна располагаться горизонтально и при этом сцепление с поверхностью должно быть достаочно большим - ни внешнее магнитное поле, ни воздействие вибрирующего зонда (режим тейпинга) не должны сдвигать НП. Было показано, что при закреплении НП на проводящем скотче поверхность последнего препятствовала измерениям, в первую очередь, из-за своей неровности. НП, нанесенные на поверхность полимера без какого-либо закрепления оказались слишком подвижными. Удовлетворительные результаты дал только третий способ фиксации - нанесение проволок на поверхность с последующим запылением тонким слоем меди (методом термического распыления в вакууме). Можно предположить, что в последнем случае дости- гались несколько эффектов - дополнительная фиксация НП, отвод статического электричества и предотвращение окисления самой НП. В то же время на характер МСМ-изображения тонкий слой меди заметного влияния не оказывал.

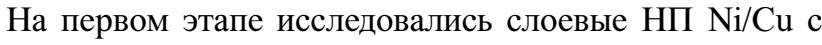
толщиной слоев около $100 \mathrm{~nm}$. Изучалась отдельная НП без приложения внешнего магнитного поля. Результаты АСМ- и МСМ-измерений приведены на рис. 11.

На АСМ-изображении видны чередующиеся полосы (рис. $11, a$, период чередования - около $100 \mathrm{~nm}$ ), которые, очевидно, соответствуют различным слоям НП. Отметим, что при сканировании МСМ-зондом кажущаяся ширина НП (диаметр) гораздо больше реального диаметра НП из-за эффекта свертки [20,21]. Поэтому истинный диаметр НП корректнее оценивать по высоте изображения - эта величина составила около $110 \mathrm{~nm}$, что весьма близко к заявленному диаметру проволоки. 
МСМ-изображение (рис. $11, b$ ) характеризует магнитное взаимодействие зонда с поверхностью: на нем видны светлый, темный и нейтральный контрасты. Светлый соответствует отталкиванию магнитного зонда от поверхности из-за взаимодействия одинаковых магнитных полюсов иглы и образца. Темная область соотвествует притяжению МСМ-зонда к поверхности при взаимодействии полюсов разного знака. По приведенному МСМ-изображению можно сказать, что проволока имеет неоднородно намагниченную структуру. Хотя четких доменных границ не наблюдается, можно утверждать, что проволока разбита на магнитные и немагнитные области. Согласно проведенным ПЭМ-измерениям данных НП, очевидно, что каждая из этих областей захватывает несколько медных и никелевых слоев.

На втором этапе НП исследовались в присутствии внешнего магнитного поля, которое прикладывалось вдоль их оси. АСМ-изображение НП представлено на рис. 12,a. Здесь также можно видеть чередование слоев и оценить диаметр НП (несколько более $100 \mathrm{~nm}$ ). MCM-изображение в поле $+16 \mathrm{mT}$ (поле направлено сверху вниз относительно плоскости рисунка) представлено на рис. 12, $b$. Далее было приложено внешнее магнитное поле величиной $-16 \mathrm{mT}$ (поле направлено снизу вверх относительно плоскости рисунка). МСМ-изображение проволоки в данном поле представлено на рис. $12, c$.

Из рисунка видно, что проволока в обоих случаях не находится в однородно намагниченном состоянии. Присутствуют чередующийся контраст, связанный с чередованием областей различной намагниченности. Сравнивая два МСМ-изображения в противоположных магнитных полях, можно заметить, что изменилась ориентация намагниченности в верхней и средней части проволоки. Однако перемагнитить всю НП не удалось.

Отметим, что ранее проведенные магнитометрические измерения (для образца из массива НП) позволили оценить коэрцитивную силу для таких НП. Она составляла $13.5 \mathrm{mT}$, а поле анизотропии - порядка $300 \mathrm{mT}$. Представляется вполне естественным, что при таких величинах невозможно получить полностью однородно намагниченную проволоку и наблюдать ее перемагничивание в противоположно направленных магнитных полях напряженностью $\mathrm{mT}$. Однако поскольку используемые поля несколько больше коэрцитивного поля, наблюдается частичная перестройка намагниченности в проволоке.

Также исследовались слоевые НП $\mathrm{Co} / \mathrm{Cu}$ с толщиной слоев около $250 \mathrm{~nm}$.

В отличие от предыдущего образца, магнитный материал - кобальт - имеет более высокие значения намагниченности. Другим отличием является то, что увеличение расстояния между магнитными слоями может привести к уменьшению их взаимодействия. В этом случае может наблюдаться конкуренция противоположных процессов: уменьшение и увеличение магнитостатического взаимодействия. Полученные
АСМ- и МСМ-изображения отдельной НП представлены на рис. 13.

Приведенные МСМ-изображения показывают, что в отсутствие внешнего магнитного поля проволока имеет чередующийся магнитный контраст с периодичностью 260-300 nm, близкой к толщине слоев образца. Приложение внешнего поля приводит к намагничиванию образца (отметим, что измеренная для массива коэрцитивная сила - $17 \mathrm{mT}$ - несколько выше прикладываемого магнитного поля). Сравнение никелевого и кобальтового образцов позволяет предположить, что второй перемагничивается труднее.

\section{4. Заключение}

В работе определены режимы получения нанопроволок с чередующимися слоями (магнитный-немагнитный металл) различной толщины в полимерной матрице трековой мембране на основе ПЭТФ. Показано, что НП с одинаковой толщиной слоев растут в порах мембраны при применении режима протекания одинакового заряда в импульсе тока в процессе электросаждение металла из электролита. Выявлено, что при описанных нами условиях и режимах роста НП (составе электролита, температуре и ростовом напряжении) уменьшение толщины слоев в НП за счет сокращения времени импульса (соответственно, протекшего заряда) возможно только до толщин $10-15 \mathrm{~nm}$. При дальнейшем уменьшении толщины слоя наблюдаются изменения в элементном составе соседних слоев. Фактически попытки получить более тонкие слои приводят к размытию их границ, и, в некоторых случаях, возникают структуры типа „стержень-оболочка“. Показано, что режим „паузы“ во время роста НП приводит к тому, что слои разного состава имеют разную толщину.

Петли гистерезиса для двух предельных взаимных ориентаций магнитного поля и оси проволок (,in-plane“ и „out-of-plane“ ) при толщине слоев 50-100 nm, практически не различаются. В то же время для НП с более толстыми слоями, 250 и $500 \mathrm{~nm}$, наблюдается заметное различие в магнитном поведении, связанное с появлением одноосной анизотропии (направления легкого намагничивания вдоль оси роста НП).

По результатам магнитно-силовой микроскопии можно сделать вывод о том, что для слоевых НП область с одинаковым направлением вектора намагниченности может включать в себя как один слой (в случае толщины слоев $250 \mathrm{~nm}$ ), так и несколько магнитных слоев (для НП с толщиной слоев $100 \mathrm{~nm}$ ). Внешнее магнитное поле с индукцией, сравнимой по величине с коэрцитивной силой, приложенное вдоль оси НП, может приводить к перестройке намагниченности в НП.

\section{Благодарности}

Авторы благодарят П.Ю. Апеля (ОИЯИ, Дубна) за предоставление образцов, С.А. Бедина (ИК 
РАН-МПГУ) за помощь в электроосаждении, С.А. Хечумяна (ИК РАН-физ.-фак. МГУ) за проведение рентгеноструктурных исследований.

\section{Финансирование работы}

Синтез и микроскопия выполнены при поддержке Министерства науки и высшего образования в рамках выполнения работ по Государственному заданию ФНИЦ „Кристаллография и фотоника“ РАН. Магнитометрия и МСМ-исследования проводились в рамках Государственного задания КФТИ ФИЦ КазНЦ РАН № АААА-А18-118041760011-2. В части работ использовалось оборудование ЦКП ИК РАН.

\section{Список литературы}

[1] C.R. Martin. Science 266, 1961 (1994).

[2] S.K. Chakarvarti, J. Vetter. Nuclear Instrum.Meth. Phys. Res. 62, 1, 109 (1991).

[3] J. Vetter, R. Spohr. Nucl. Instrum. Meth. Phys. Res. 79, 1-4, 691 (1993).

[4] T.M. Whitney, J.S. Jiang, P.C. Searson, C.L. Chien. Science 261, 1316 (1993).

[5] К.В. Фролов, Д.Л. Загорский, И.С. Любутин, М.А. Чуев, И.В. Перунов, С.А. Бедин, А.А. Ломов, В.В. Артемов, С.Н. Сульянов. Письма в ЖЭТФ 105, 5, 297 (2017).

[6] Д.Л. Загорский, К.В. Фролов, С.А. Бедин, И.В. Перунов, М.А. Чуев, А.А. Ломов, И.М. Долуденко. ФТТ 60, 11, 2075 (2018).

[7] N. Lupu. Electrodeposited Nanowires and Their Applications / Ed. N. Lupu. InTech (2010).

[8] Magnetic Nano- and Microwires: Design, Synthesis, Properties and Applications / Ed. M. Vázquez. Woodhead Publishing, Elsevier (2015).

[9] А.А. Давыдов, В.М. Волгин. Электрохимия 52, 9, 905 (2016).

[10] L. Piraux, J.M. George, J.F. Despres, C. Leroy, E. Ferain, R. Legras, K. Ounadjela, A. Fert. Appl. Phys. Lett. 65, 2484 (1994).

[11] A. Blondel, J. Meier, B. Doudin, J-Ph. Ansermet, K. Attenborough, P. Evans, R. Hart, G. Nabiyouni, W. Schwarzacher. J. Magn. Magn. Mater. 148, 317 (1995).

[12] K. Liu, K. Nagodawithana, P.C. Searson, C.L. Chien. Phys. Rev. 51, 73 (1995).

[13] L. Wang, K.Yu. Zhang, A. Metrot, P. Bonhomme, M. Troyon. Thin Solid Films 288, 86 (1996).

[14] A. Blondel, B. Doudin, J.P. Ansermet. J. Magn. Magn. Mater. 165, 1-3, 34 (1997).

[15] Yu.P. Ivanov, A. Chuvilin, L.G. Vivas, J. Kosel, O. ChubukaloFesenko, M. Vazques. Nature Sci. Rep. 6, 23844 (2016).

[16] Yu.P. Ivanov, A. Chuvilin, S. Lopatin, H. Mohammed, J. Kosel. ACS Appl. Mater. Interfaces 9, 16741 (2017).

[17] D. Magnin, V. Callegari, Matefi-Tempfli, M. Matefi-Tempfli, K. Glinel, A.M. Jonas, S. Demoustier-Champagne. Biomacromolecules 9, 2517 (2008).
[18] Д.К. Нургалиев, П.Г. Ясонов. Коэрцитивный спектрометр. Патент РФ № 81805. Бюл. ФИПС № 9 (2009).

[19] Д.А. Бизяев, А.А. Бухараев, Р.И. Хайбуллин, Н.М. Лядов, Д.Л. Загорский, С.А. Бедин, И.М. Долуденко. Микроэлектроника 47, 3, 212 (2018).

[20] А.А. Бухараев, Н.В. Бердунов, Д.В. Овчинников, К.М. Салихов. Микроэлектроника 26, 3, 163 (1997).

[21] P. Markiewicz, S.R. Cohen, A. Efimov, D.V. Ovichinnikov, A.A. Bukharaev. Probe Microscopy 1, 355 (1999).

Редактор Е.Ю. Флегонтова 